\title{
The Effect of Solar Reflective Cover on Soak Air Temperature and Thermal Comfort of Car Parked under the Sun
}

\author{
A.A. Lahimer ${ }^{a}$, M.A. Alghoul*, b,, K. Sopian *, a , N. G. Khrit ${ }^{a}$ \\ ${ }^{a}$ Solar Energy Research Institute, Universiti Kebangsaan Malaysia, 43600 Bangi, Selangor, Malaysia \\ ${ }^{b}$ Energy and Building Research Center, Kuwait Institute for Scientific Research, P.O. Box 24885, Safat 13109, \\ Kuwait \\ ${ }^{c}$ Center of Research Excellence in Renewable Energy (CoRe-RE), Research Institute, King Fahd University of \\ Petroleum and Minerals (KFUPM), Dhahran 31261, Saudi Arabia \\ *Corresponding authors: dr.alghoul@gmail.com (M.A.Alghoul), ksopian@ukm.edu.my (K. Sopian)
}

\begin{abstract}
Parking a vehicle under the sun for a short period of time can rapidly increase the interior air cabin temperature no matter in clear sky days or even in partially cloudy days. These circumstances can be anxieties to car occupants upon entry. The aim of this paper is to evaluate experimentally the effect of solar reflective cover (SRC) on vehicle air temperature and cabin thermal comfort. Experimental measurements of parked cars were conducted in UKM, Bangi city, Malaysia (latitude of $2.9^{\circ} \mathrm{N}$ and longitude of $101.78^{\circ} \mathrm{E}$ ) under partially cloudy day where average ambient temperature is $33^{\circ} \mathrm{C}$. The experimental measurements cover the following cases: case (I): car with/ without SRC (at different measurement time); Case (II): using two identical cars concurrently (SRC versus baseline); Case (III): using two identical cars concurrently (solar reflective film (SRF) versus baseline) and Case (IV): using two identical cars concurrently (SRF versus SRC). Experimental results dedicated to case (I) revealed that the maximum cabin air temperature with $\mathrm{SRC}\left(39.6^{\circ} \mathrm{C}\right)$ is significantly lower than that of baseline case $\left(57.3^{\circ} \mathrm{C}\right)$. This leads to temperature reduction improvement of $31 \%$ and the difference between the cabin and the ambient air temperature was minimized by approximately $73 \%$. In addition, the results revealed that the air temperature at breath level of car with SRC dropped to comfort temperature $\left(27^{\circ} \mathrm{C}\right)$ after $7 \mathrm{~min}$ while baseline car reached comfort temperature after 14 min. Results of the other cases are discussed inside the paper. Overall, it is learned that SRC is found superior as an efficient thermal insulation system limits solar radiation transmission into the cabin through the glass; keeps cabin air temperature close to the ambient temperature; and provide acceptable thermal environment to the occupants as they settle into their parked car.
\end{abstract}

Keywords: parked vehicle under the sun, cabin soak air temperature, solar reflective aluminum cover, cabin thermal comfort.

\section{INTRODUCTION}

Most vehicles have large-sized glazed surfaces area with respect to the total cabin surface area. Large percentage of glass is inclined with respect to the horizontal which maximizes the entry of the incident solar radiation. (Rugh and Farrington 2008) claimed that typically $50 \%$ to $75 \%$ of the thermal energy entering the car cabin is due to transmitted and absorbed solar energy from the glazing. Windshield alone accounts for more than $40 \%$ of heat transmitted into the cabin (Rugh, Chaney et al. 2013). Therefore, the incident solar radiation transmitted through the glass of the car is the main cause of high cabin temperature, it can increase the interiors temperature for the first 15 min at a rate of $1{ }^{\circ} \mathrm{C} /$ min (Parker 1988; McLaren, Null et al. 2005). As a result, the extreme maximum cabin temperature which can be as much as two times of the ambient temperature or even more can be reached at about 45 min. The unpleasant environment will take long time (usually $15 \mathrm{~min}$ ) to cool down by A/C system to reach human thermal comfort level. In addition, this peak cooling load has a negative impact on $\mathrm{A} / \mathrm{C}$ size, fuel consumption and emission. Therefore, blocking the sun rays is the only approach that can have a significant cabin temperature reduction. For example, (Mezrhab and Bouzidi 2006) achieved a considerable reduction of the temperature inside the compartment up to $10^{\circ} \mathrm{C}$ by using reflecting glazing (low transmissivity and absorptivity). (John P. Rugh, Lawrence Chaney et al. 2007) achieved $9.7^{\circ} \mathrm{C}$ temperature reduction by using solar-reflective glass and solar-reflective paint. (Rugh and Farrington 2008) recommended that, exterior mounted window shades would be more suitable than interior window shades. (Hoke and Greiner 2005; Rugh and Farrington 2008; Levinson, Pan et al. 2011) studied the effect of solar reflectance 
on the cabin air soak temperature (low solar reflectance for dark color and high solar reflectance for light color). Based on their studies, the cabin air soak temperature was reduced by approximately $1^{\circ} \mathrm{C}$ for each 0.1 increase in the solar reflectance of the cabin coatings.

\section{Materials ANd Methods}

The objective of this study is to study the effect of SRC (a commercially available half top cover which made of aluminum laminated with non-woven; low solar absorptance and low thermal emittance) on cabin soak air temperature, thermal comfort and AC compressor of car parked under the sun during cloudy days. In addition to compare SRC to other thermal load reduction strategies such as solar reflective film SRF.

\subsection{Experimental Setup}

Two identical cars with same interior and exterior were parked, side by side, in an open grassy space under sun and oriented facing south without shadow interference during the experimental measurements. The seats were adjusted to the same position and all windows remained closed throughout the test. For the evaluation of cabin soak temperature and thermal comfort, each vehicle was instrumented with HD32.3A (fig.1) to measure the interior parameters (globe thermometer temperature $T_{g}$, natural wet bulb temperature $T_{n}$, environment temperature $T$, relative humidity $R H$ and air speed $\mathrm{V}_{\mathrm{a}}$ ) in $60 \mathrm{sec}$ intervals at breath-level height midway between the front seat headrests. Weather data such as ambient temperatures were measured by TECMAN TM820M (fig.1) at a nearby building and global horizontal solar irradiance was obtained by SP-110: self-powered silicon-cell pyranometers (fig.1). The average values of the ambient temperature and global horizontal solar irradiance were considered.

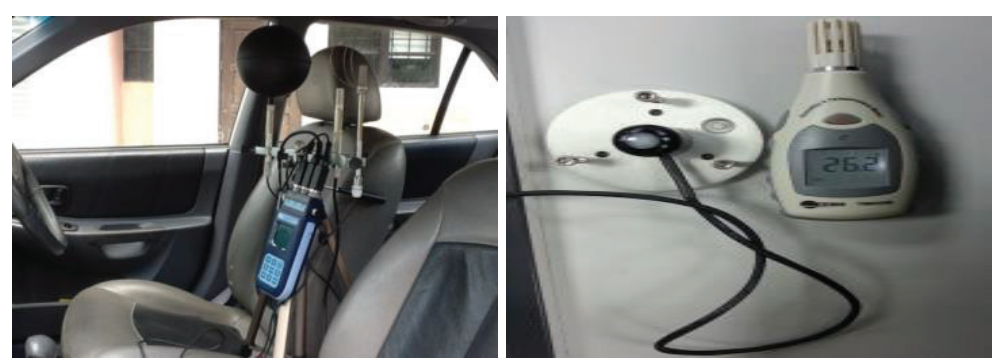

Fig 1: Thermal comfort and weather instruments used in this study

\subsection{Experimental Procedures}

Sets of experimental measurements on parked cars have been conducted for the following cases, including:

- $\quad$ Case (I) using one car with/ without SRC (measurement at different time)

In May 23, 2016, a thermal soak test from12:00-1:00 PM was performed on one car covered with SRC followed immediately by $18 \mathrm{~min}$ cooling. The initial cabin and average ambient temperatures were $22^{\circ} \mathrm{C}$ and $32^{\circ} \mathrm{C}$, respectively. After 5min from the end of the previous cooling trial, another soaking experiment from 1:25-2:25 PM was performed on the same car but without SRC followed immediately by $18 \mathrm{~min}$ cooling trial. The initial cabin temperature in this test was $27.6^{\circ} \mathrm{C}$ and the average ambient temperature was $33^{\circ} \mathrm{C}$.

- $\quad$ Case (II) using two identical cars concurrently (SRC versus baseline)

Soaking trial from 12:55-2:10 PM (75min) was performed on two identical cars in October 15, 2016. One car was covered with SRC and the other one served as a baseline and remained unmodified as shown in fig 2 . The aim was to study the effect of SRC at equally initial cabin and ambient temperatures for both cars. The average ambient temperature and the solar irradiance were $35^{\circ} \mathrm{C}$ and $696 \mathrm{~W} / \mathrm{m}^{2}$, respectively. 


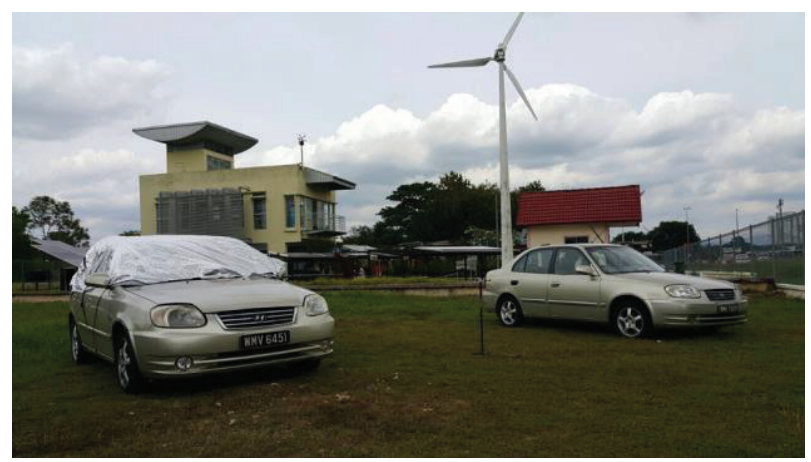

Fig 2: Two identical cars with and without solar reflective cover at the experimental field

- $\quad$ Case (III) using two identical cars concurrently (SRF versus baseline)

In November 13, 2016, a thermal soaking test from 12:30-1:04 PM (34min) was performed on two identical cars followed immediately and simultaneously by $21 \mathrm{~min}$ cooling trial. One car served as a baseline without integrating any temperature reducing techniques; while the other one was fitted with SRF on every window (about $65 \%$ infrared rejection) except the front windshield remained unmodified. Prior to testing, maximum fan speed and recirculation mode were used in each vehicle to monitor and adjust the $\mathrm{AC}$ vent temperatures. Accordingly, the vent temperatures set at the same values for both cars to assure similar AC cooling performance. The average initial cabin temperatures for both cars were $36.7^{\circ} \mathrm{C}$. The aim was to study the effect of SRF on cabin soak air temperature and occupants thermal comfort.

- $\quad$ Case (IV) using two identical cars concurrently (SRC versus SRF)

Immediately, after the end of the previous cooling trial, another soaking experiment from1:27-2:33 PM was performed on the same cars but the baseline was covered with SRC followed immediately and simultaneously by 16 min cooling trial. The average initial cabin temperatures for both cars were $37.6^{\circ} \mathrm{C}$. The average ambient temperature and the solar irradiance were $33.8^{\circ} \mathrm{C}$ and $779 \mathrm{~W} / \mathrm{m}^{2}$, respectively for both trials.

\section{RESULTS AND DISCUSSION}

\subsection{Cabin Soaks Air Temperature Comparison}

\section{- $\quad$ Case (I)}

The cabin car measurements started after cooling the cabin at comfort level for 20 min using the AC system then it is turned off. As the AC turned off in the parking lot, the results showed that the cabin air temperature rapidly reached the outside ambient temperature within the first 5 minutes at a rate of $2^{\circ} \mathrm{C} / \mathrm{min}$. This result was also observed in (McLaren, Null et al. 2005).

Fig. 3 shows one hour of car soak air temperature under direct sun. It can be seen that the maximum cabin air temperature observed for both cases were reached at the same period of time at about 45 min regardless of any approach used, which was expected when the same car was used for the study. Also, it can be seen in Fig. 3 that the maximum cabin air temperature for case I with $\operatorname{SRC}\left(39.6^{\circ} \mathrm{C}\right)$ is significantly lower than that of baseline case $(57.3$ $\left.{ }^{\circ} \mathrm{C}\right)$. The breath level air temperature in case I with SRC is approximately $17.7^{\circ} \mathrm{C}$ cooler than the baseline of case I without SRC. These results could be attributed to the low solar low thermal emittance and absorptance of the cover, which lead to maintain an average temperature difference of $5^{\circ} \mathrm{C}$ between the cabin and the ambient. However, the soaking test results showed that the SRC demonstrated a temperature reduction improvement of $31 \%$, and consequently reducing the heat gained by the cabin. This means that the difference between the cabin and the ambient air temperature was reduced by approximately $73 \%$ by using SRC. 


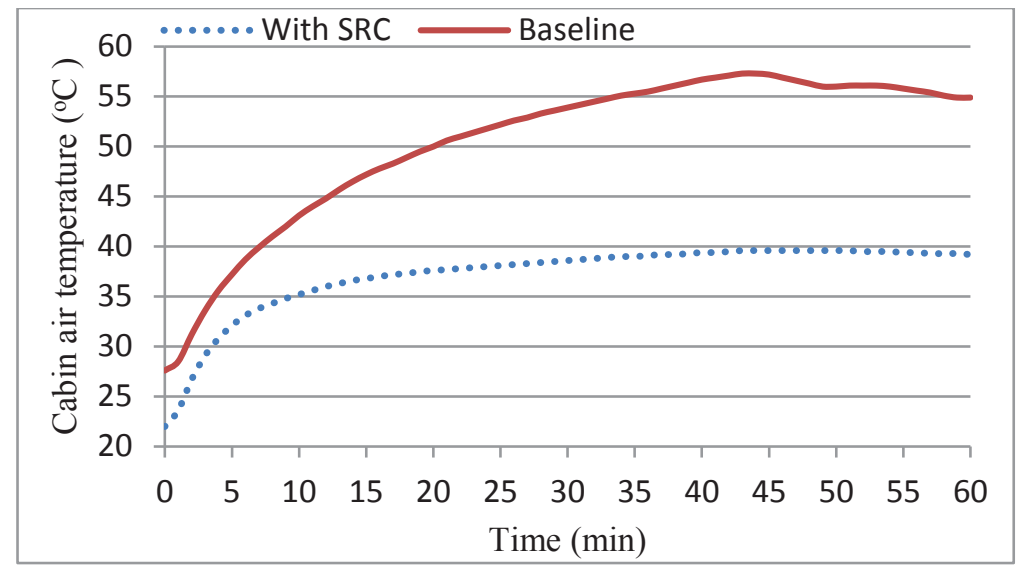

Fig 3: Comparison of cabin soaks air temperature at breath level (SRC versus baseline) using one car with measurements at different time, case I

\section{- Case (II)}

In this trial, both identical cars were subjected to $75 \mathrm{~min}$ thermal soak trial under direct sun and started the soaking trial with an initial cabin air temperature as same as the average ambient air temperature. Fig. 4 shows that, for the first $15 \mathrm{~min}$ the cabin air temperature in the car with SRC increased sharply till reached the maximum value of $42^{\circ} \mathrm{C}$ and then almost continued steady until the end of $1 \mathrm{~h}$. SRC was able to maintain an average temperature difference of $6^{\circ} \mathrm{C}$ between the cabin and the ambient. However, the cabin air temperature in the car without SRC also increased sharply for the first $15 \mathrm{~min}$ and then continued to increase till it reached the maximum value of $55.4^{\circ} \mathrm{C}$ at the end of $1 \mathrm{~h}$ of the soaking test. This resulted in breath level air temperature difference approximately $13.4^{\circ} \mathrm{C}$ between the SRC and baseline case. Although for the car without SRC it should be also noted that the cabin air temperature have to increase or at last remains steady during the peak solar irradiance (12:00-3:00 PM), however the temperature drop is contributed to the weather condition as the sky become very cloudy.

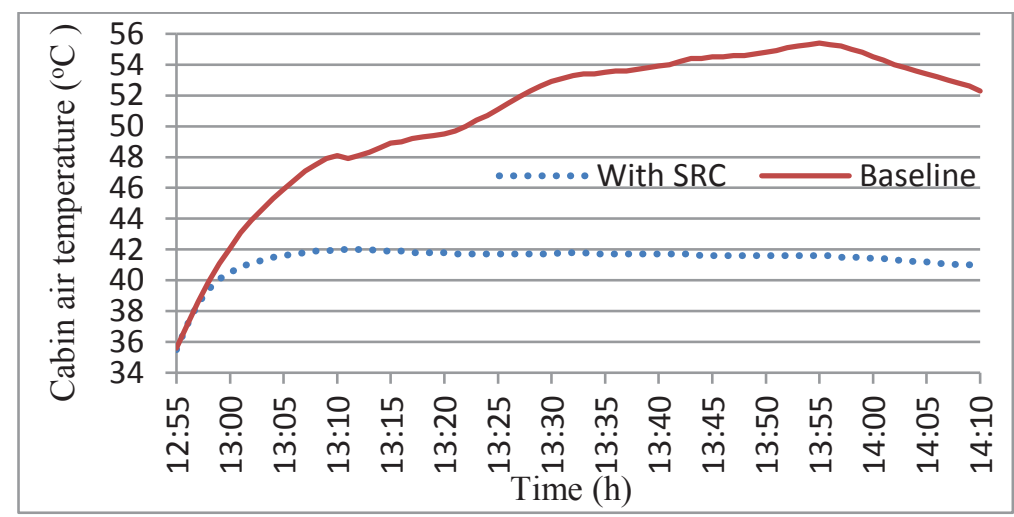

Fig 4: Comparison of cabin soaks air temperature at breath level (SRC versus baseline) using two identical cars concurrently

\section{- Case (III)}

Fig. 5 shows the soak cabin air temperatures of the baseline and SRF cases. At the beginning of the thermal soak trial, the air temperatures inside SRF car were hotter than the baseline temperatures. In fact, the breath-level air temperatures in the baseline case were approximately $0.83^{\circ} \mathrm{C}$ cooler than in the case with the SRF. After $18 \mathrm{~min}$ the soak cabin air temperatures for the baseline case and the SRF experiments are almost identical, where the average difference in cabin air temperature between the two cars was $0.39^{\circ} \mathrm{C}$ and the maximum difference was $0.1^{\circ} \mathrm{C}$. This 
shows inability of SRF in reducing the interior cabin air temperature and does not have any significant difference from the baseline.

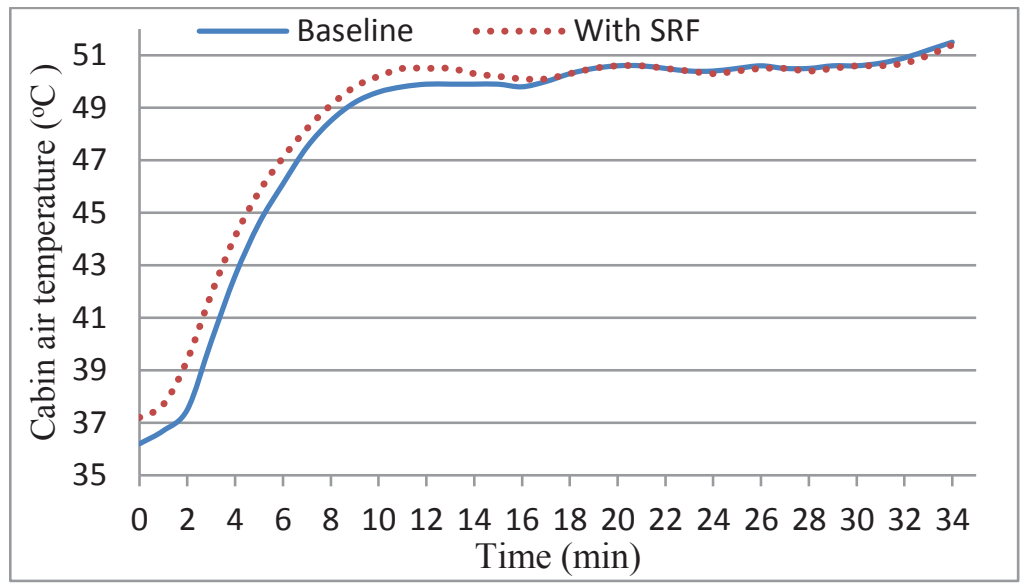

Fig 5: Comparison of cabin soaks air temperature at breath level (SRF versus baseline) using two identical cars concurrently

\section{- $\quad$ Case (IV)}

The soak cabin air temperatures of SRC and SRF cases were compared and shown in fig. 6. The air temperatures increased sharply in SRC case until $7 \mathrm{~min}$ and then become almost steady with maximum value of $45.9^{\circ} \mathrm{C}$. On the other hand, in SRF case the air temperatures increased sharply until $14 \mathrm{~min}$ and then continue to increase to reach the maximum value of $60.1^{\circ} \mathrm{C}$. Moreover, the breath-level air temperatures in the case with the SRC were approximately $14.2^{\circ} \mathrm{C}$ cooler than the SRF case, demonstrating a significant impact from SRC for this thermal soak test. However, as expected, the SRF case has the highest interior temperatures during thermal soak due to the direct solar radiation transmitted through the front windshield and also windows tint allows some. In addition, windows tint leads to increase the absorption due to its color and become an extra source of heat.

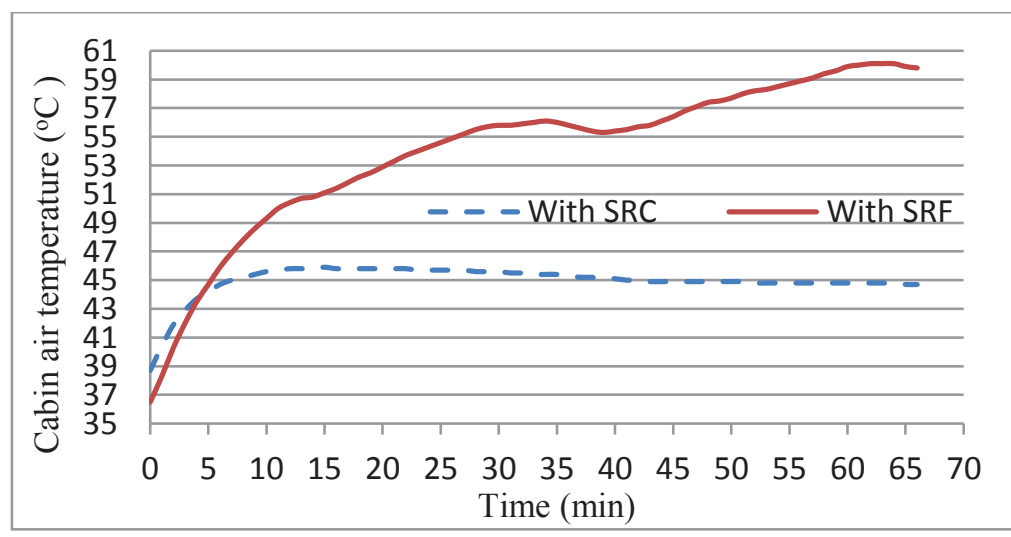

Fig 6: Comparison of cabin soaks air temperature at breath level (SRC versus SRF) using two identical cars concurrently

\subsection{Thermal Comfort Evaluation}

In this round of analysis, the comfort level is considered with PMV between ( -0.50 and 5$)$ and the PPD is less than $10 \%$; therefore comfort temperature (Tc) is $27^{\circ} \mathrm{C}$. The cooling down measurements of cases (I, III and IV) are plotted 
in figures 7, 8 and 9 respectively. Since, the cooling down behavior of the other cases is similar to Case I, however, the discussion will be dedicated to case I only.

After $1 \mathrm{~h}$ of soak under direct sun, 18 min transient temperature measurements using AC system to cool-down the cabin for both trials in case I are shown in Fig 7. In general, it is clearly seen that the cabin air temperature in case I with SRC cooled faster than baseline case (without SRC) since the cooling down trail started. The cabin breath level air temperature dropped to comfort temperature $\left(27^{\circ} \mathrm{C}\right)$ after $7 \mathrm{~min}$ in case I with SRC while baseline case reached comfort temperature after $14 \mathrm{~min}$. Thus, it can be concluded that occupants used the cover will reach the comfort level 7 min faster than baseline case during the cool-down trials. The time difference is attributed to the lower initial air temperature of the cabin when it started the cool-down for case I with SRC, whereas the cabin for baseline case started the cool-down with a higher air temperature. However, at the end of the cooling down trials, the air temperature dropped to $21.5^{\circ} \mathrm{C}$ with SRC and approximately $24.5^{\circ} \mathrm{C}$ in baseline case. A temperature difference of approximately $3^{\circ} \mathrm{C}$ is still existed between the modified and baseline cases.

The lessons learned from figures (3, 4 and 7) that in both situations (with/without SRC) at the end of the soaking test, the comfort indices values were out of the comfort zone. But the occupants will still feel a significant temperature reduction in case with SRC upon entry. Therefore, reducing the thermal solar loads using SRC could reduce the exposure time of occupants for high temperature, thereby reducing their thermal stress and anxiety and improving vehicle fuel consumption.

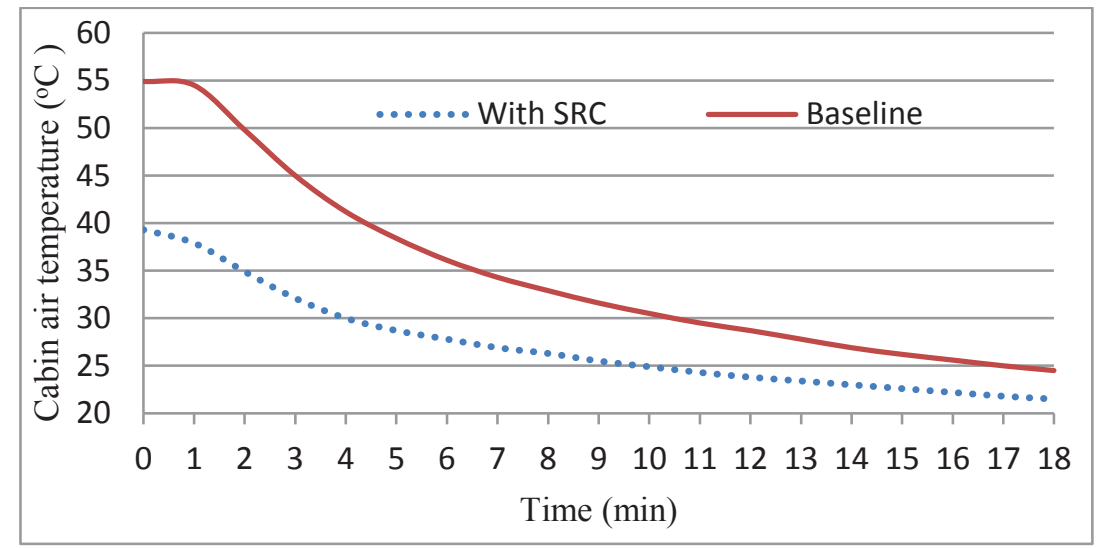

Fig 7: Car cooling down (SRC versus baseline) for case (I)



Fig 8: Cooling down of two identical cars (SRF versus baseline) for case (III) 


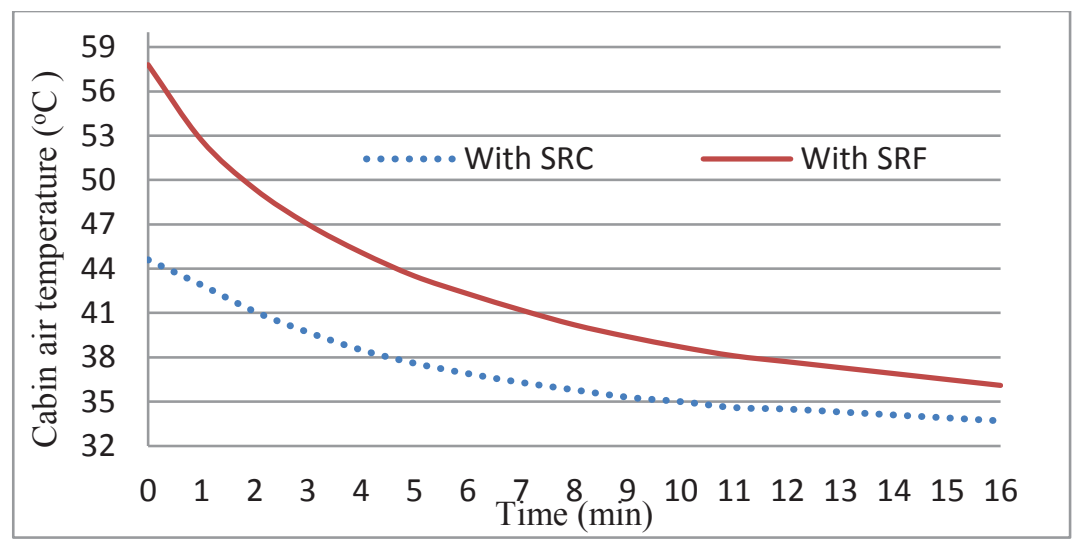

Fig 9: Cooling down of two identical cars (SRC versus SRF) for case (IV)

\section{CONCLUSION}

In the work, experimental approach is adopted to evaluate the effect of SRC on vehicle soak air temperature, thermal comfort under partial cloudy sky conditions of UKM, Bangi city, Malaysia. The results confirmed the significant effects of SRC over other approaches such as SRF in terms of cabin soak air temperature, reducing time required to achieve thermal comfort and preventing cracking and fading of cabin's interior.

\section{References}

1. Fanger, P. O. (1970). Thermal comfort: Analysis and applications in environmental engineering, Danish Technical Press.

2. Hoke, P. B. and C. M. Greiner (2005). Vehicle Paint Radiation Properties and Affect on Vehicle Soak Temperature, Climate Control System Load, and Fuel Economy, SAE Technical Paper 2005-01-1880, doi:10.4271/2005-01-1880. Detroit, Michigan, USA, Warrendale, PA: SAE International Publication.

3. John P. Rugh, Lawrence Chaney, et al. (2007). Reduction in Vehicle Temperatures and Fuel Use from Cabin Ventilation, Solar-Reflective Paint, and a New Solar-Reflective Glazing. SAE World Congress. : 1-8. Detroit, Michiga, USA, Warrendale, PA : SAE International Publication

4. Levinson, R., H. Pan, et al. (2011). "Potential benefits of solar reflective car shells: Cooler cabins, fuel savings and emission reductions." Applied Energy 88(12): 4343-4357.

5. McLaren, C., J. Null, et al. (2005). "Heat Stress From Enclosed Vehicles: Moderate Ambient Temperatures Cause Significant Temperature Rise in Enclosed Vehicles." Pediatrics 116(1): e109-e112.

6. Mezrhab, A. and M. Bouzidi (2006). "Computation of thermal comfort inside a passenger car compartment." Applied Thermal Engineering 26(14-15): 1697-1704.

7. Rugh, J. (2002). Integrated Numerical Modeling Process for Evaluating Automobile Climate Control Systems Paper presented at Future Car Congress, Crystal City, VA, USA, Paper \# 2002-01-1956,Society of Automotive Engineers.

8. Rugh, J., L. Chaney, et al. (2013). Impact of Solar Control PVB Glass on Vehicle Interior Temperatures, AirConditioning Capacity, Fuel Consumption, and Vehicle Range. SAE 2013 World Congress \& Exhibition. 2013-01-0553. U.S, National Renewable Energy Laboratory (U.S.)) ; 5400-57489.

9. Warrendale, Penn.: Society of Automotive Engineers

10. Rugh, J. and R. Farrington (2008). Vehicle Ancillary Load Reduction Project Close-Out Report: An Overview of the Task and a Compilation of the Research Results, National Renewable Energy Laboratory. USA, Golden Publication, CO. 
11. Rugh, J. P., T. J. Hendricks, et al. (2001). Effect of Solar Reflective Glazing on Ford Explorer Climate Control, Fuel Economy, and Emissions. International Body Engineering Conference. Detroit, MI, USA, Society of Automotive Engineers Publication. 